\title{
TWO-PHASE TWO-STAGE HF MATRIX CONVERTER FOR SUPPLVING TWO-PHASE MOTOR LOAD
}

This paper deals with the two-stage two-phase electronic systems with orthogonal output voltages and currents - DC/HF_AC/2AC. It also introduces the design and prototype of two-stage $D C / H F \_A C / 2 A C$ high frequency converter with two-phase orthogonal output using two singlephase matrix converters in full-bridge connection operated with the unipolar PWM. Simulation and experimental results of matrix converter for both steady and transient states for IM motors are given in the paper together with experimental verification under R-L load. The results confirm a very good time-waveform of the phase current and the system seems to be suitable for low-cost application in automotive/aerospace industries and application with high frequency voltage sources.

Keywords: Matrix Converter, Two-Phase Induction Machine TPIM, Orthogonal System.

\section{Introduction - Single-phase HF Matrix converter}

The matrix converters are among to direct converters - there is a direct conversion of the input voltage to the output voltage with another frequency. The use of high switching frequency reduces the effect of harmonic current back to the power grid. The bidirectional switches are necessary because they allow flow current in both directions. The basic connection of direct converter - matrix converter $(3 \times 3)$ is shown in Fig. 1a. From this scheme is derived the connection of single-phase matrix converter, Fig. 1b, [1] and [2].

The relations between output and input voltages, and between output currents and vo are:

$$
\begin{aligned}
& {\left[v_{o}(t)\right]=[M(t)] \cdot\left[v_{I}(t)\right] \text { and }} \\
& {\left[v_{o}(t)\right]=[A] \cdot\left[i_{o}(t)\right]+[B] \cdot\left[v_{o}(t)\right]}
\end{aligned}
$$

where $[M(t)]$ is modulation matrix, $m_{\alpha A}(t)=\frac{t_{\alpha A}}{T_{s e q}}$ is modulation index, $t_{a A}$ is time of switched state, with restrictions:

$$
\sum_{K=a, b, c} m_{K A}(T)=\sum_{K=a, b, c} m_{K B}(T)=\sum_{K=a, b, c} m_{K C}(T)=1
$$

a)

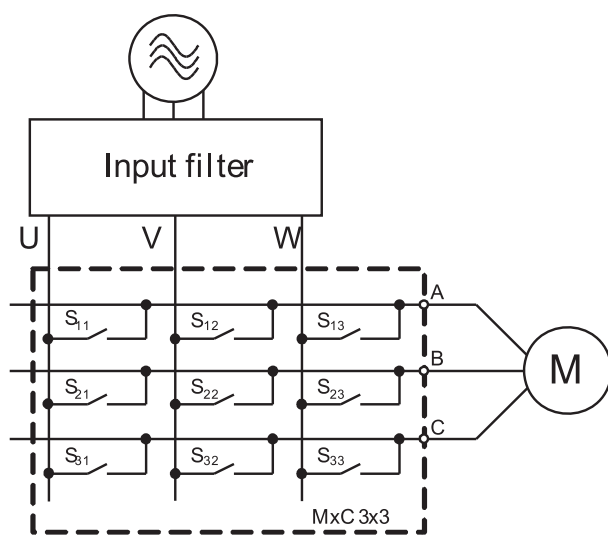

Fig. 1 Scheme of matrix converter (a) and single-phase derivation (b)

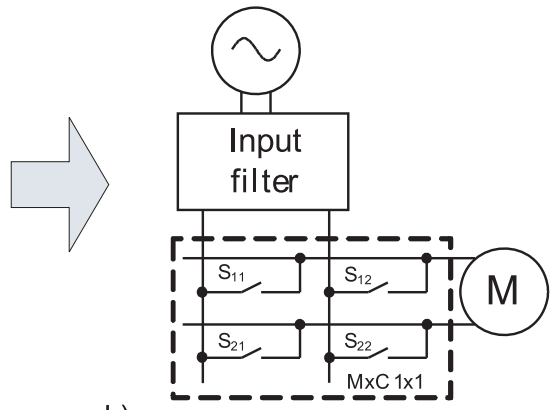

b)

ase derivation (b)

* Michal Prazenica ${ }^{1}$, Michal Kabasta ${ }^{2}$, Slavomir Kascak ${ }^{1}$, Juraj Koscelnik ${ }^{1}$, Jozef Buday ${ }^{3}$

${ }^{1}$ Department of Mechatronics and Electronics, Faculty Electrical Engineering, University of Zilina, Slovakia, E-mail: michal.prazenica@fel.uniza.sk

${ }^{2}$ ABB s.r.o., Ostrava, Czech Republic

${ }^{3}$ EVPU a.s., Nova Dubnica, Slovakia 


\section{Two-stage two-phase systems with $\mathrm{HF}$ AC interlink and matrix converters (DC/HF_AC/2AC)}

Two-stage two-phase systems with HF AC interlink and matrix converters (DC/HF_AC/2AC) usually consist of a single-phase voltage inverter, $\mathrm{AC}$ interlink, $\mathrm{HF}$ transformer, 2-phase $\mathrm{AC} / \mathrm{AC}$ converter and 2-phase $\mathrm{AC}$ motor. This is the best choice due to an $\mathrm{AC}$ interlink direct converter (cyclo or matrix converter). The system with matrix converter and high frequency AC interlink can generate two-phase orthogonal output with both the variable voltage and the frequency [3], [4] and [5]. The proposed scheme of twostage two-phase converter system is shown in Fig. 2. The switching frequency of the converter is rather high ( $\sim$ tens of $\mathrm{kHz})$ and the second stage operates with twice switching frequency. Since the voltages of the matrix converter system should be orthogonal ones, the second phase converter is the same as the first one and its voltage is shifted by 90 degree. The switches of the inverter operate with hard commutation, the switches of matrix converters are partially soft-commutated in the zero-voltage instants of the AC voltage interlink using unipolar PWM [6]. Therefore, the expected efficiency of the system can be higher than usually by using the classical three-phase inverter .

\section{Control of matrix converter with high-frequency input}

The theoretical analysis of single-phase matrix converter has been done, e.g. [4] and [6]. The full-bridge converter provides unipolar and bipolar PWM control. Switching-pulse-width can be determined on the basis of the equivalence of average values of reference waveform and the result is the average value of positive or negative switching pulse area during switching period [7]

The switching instant is equal to:

$$
t_{s}(k)=\frac{1}{U_{D C}} \cdot S_{\Delta}(k)
$$

and the area under sine wave during k-switched interval $S_{\Delta}(k)$ is:

$$
S_{\Delta}(k)=U_{m} \cdot \frac{m_{f}}{2 \pi} \cdot\left[\cos \left(\frac{2 \pi}{m_{f}} \cdot k\right)-\cos \left(\frac{2 \pi}{m_{f}} \cdot(k+1)\right)\right]
$$

The total harmonic distortion of the current is:

$$
\begin{aligned}
& \frac{\sqrt{\sum I_{v}^{2}}}{I_{1}}=\sqrt{\frac{I^{2}-I_{1}^{2}}{I_{1}^{2}}}=\sqrt{\left(\frac{I}{I_{1}}\right)^{2}-1}= \\
& =\sqrt{[(8.34822 / 8.34386) 2-1]}=\sim 2 \%
\end{aligned}
$$

Fourier analysis is useful and needed for the determination of total harmonic distortion of the phase current of the matrix converter. Unipolar switching strategy of one full-bridge matrix converter can be explained using Fig. 3 in greater details [4] and [8], [9], [10], [11].

\section{Simulation Experiment}

The simulation model of a two-stage converter was modeled in OrCAD programming environment, Fig. 4 and the simulation model of motor load was modeled in MatLab programming environment and they together were connected using Matlab SPLS. The simulation results of two-stage single-phase full-bridge matrix converter with R-L load are shown in Fig. 5. Both stages of converter are realized in full-bridge connection - (unipolar or bipolar PWM can be used). To protect the inverters against overvoltage surges in both stages the floating protection is used, which returns stored energy back to the DC-link and, thereby, improves the efficiency of the converter.

The simulation results show the response of the two-phase AS motor $(230 \mathrm{~V} / 150 \mathrm{~W}, 50 \mathrm{~Hz}, 2730 \mathrm{rpm})$ to step change of motor load (in open loop). At time $t=0.2 \mathrm{~s}$ the motor was loaded with torque $(M=1 \mathrm{Nm})$. The simulated waveforms during start-up of the two-phase induction machine (TPIM) supplied by two-phase switched voltage $\left(P W M, U_{D C}=350 \mathrm{~V}, f_{s w 1}=10 \mathrm{kHz}, f_{s w 2}=20 \mathrm{kHz}\right.$, $U_{\text {outAC }}=230 \mathrm{~V}, f_{\text {out }}=50 \mathrm{~Hz}$ ) voltage shifted by 90 degree are depicted in Fig. 6.

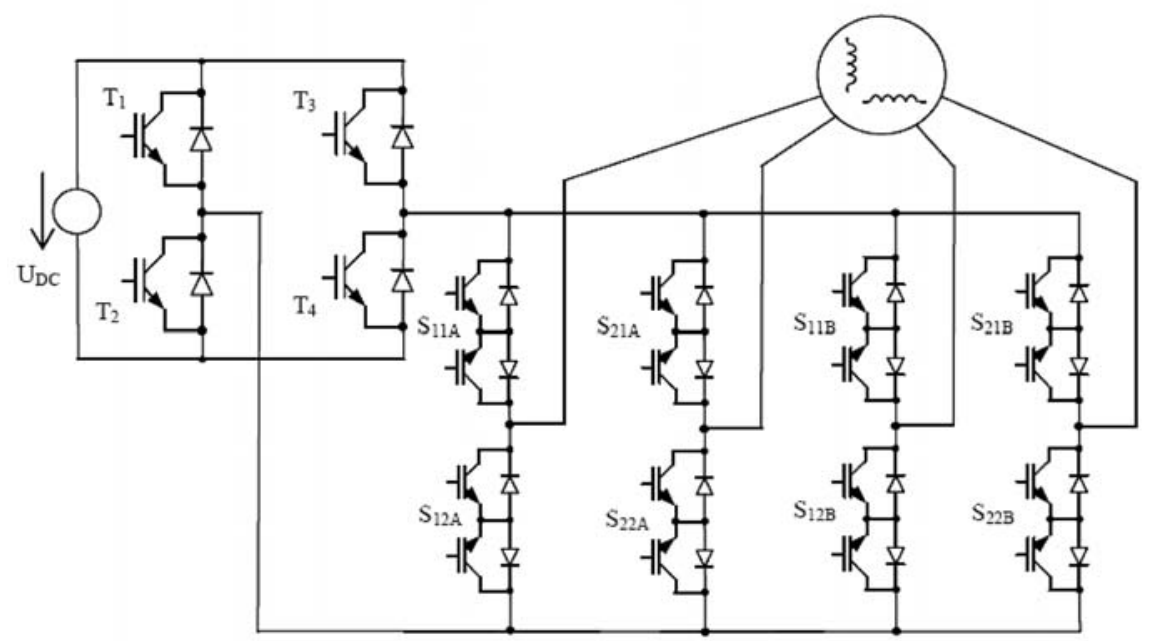

Fig. 2 Two-stage two-phase systems with HF AC interlink, matrix converters and motor load 

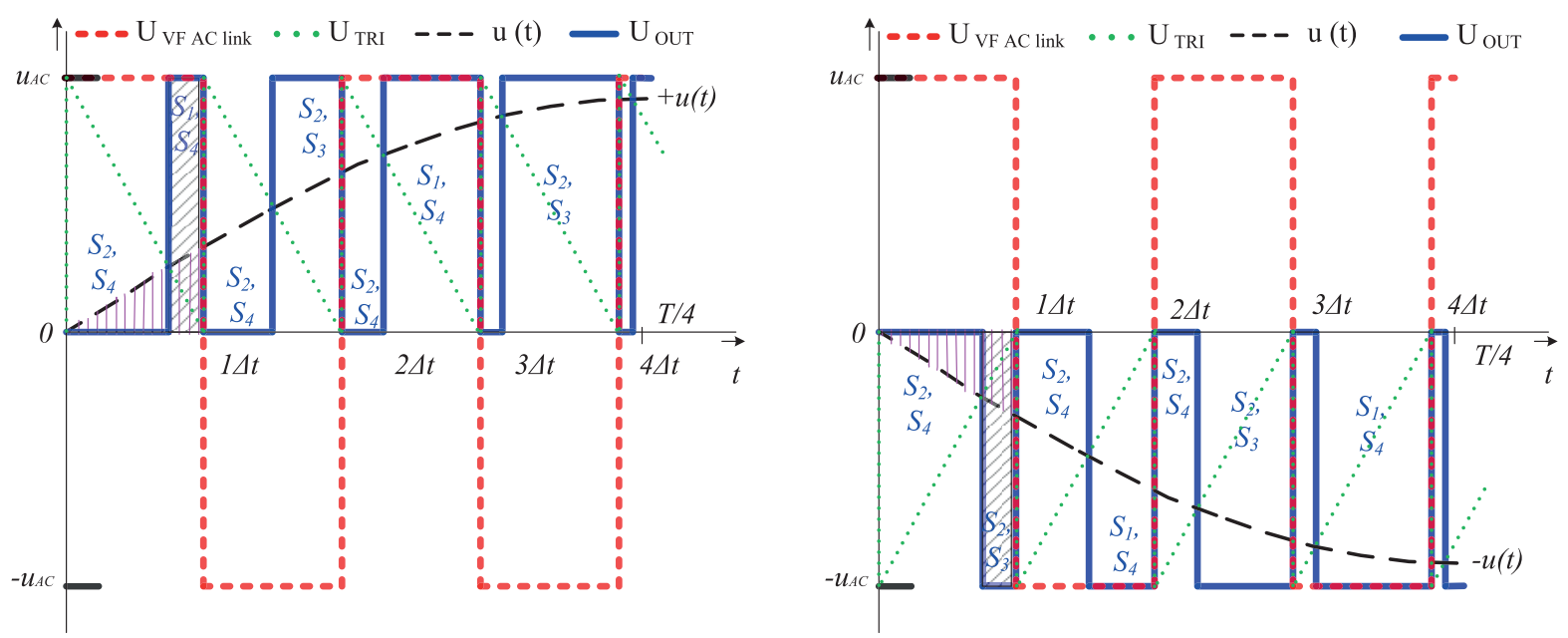

Fig. 3 Switching strategy for positive (a) and negative (b) half period of operation

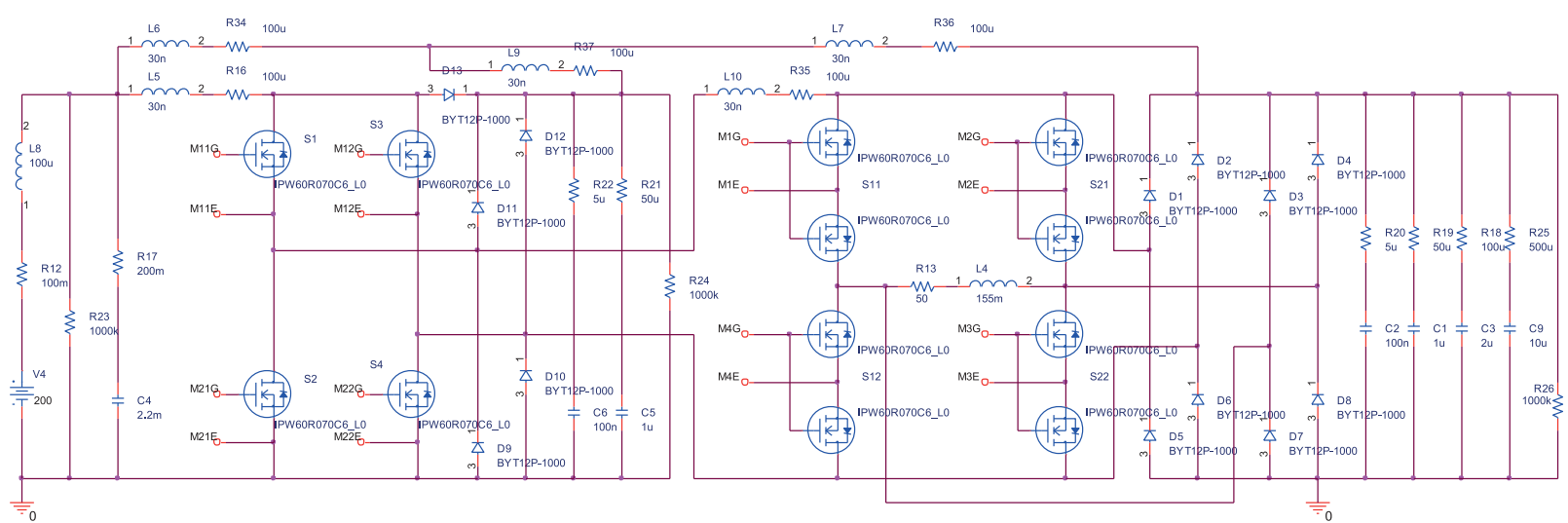

Fig. 4 Simulation model of two-stage single-phase converter

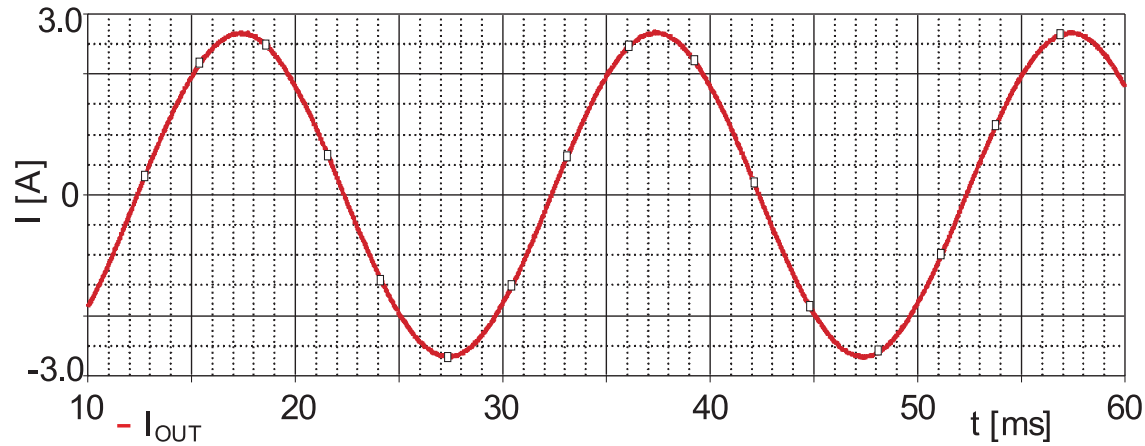

Fig. 5 Simulated waveform of output current of the single-phase converter under $R-L$ load $\left(U_{D C}=350 \mathrm{~V}, R=10 \Omega, L=30 \mathrm{mH}\right.$, $f_{S W 1}=10 \mathrm{kHz}, f_{S W 2}=20 \mathrm{kHz}, f_{\text {OUT }}=50 \mathrm{~Hz}$ ) 

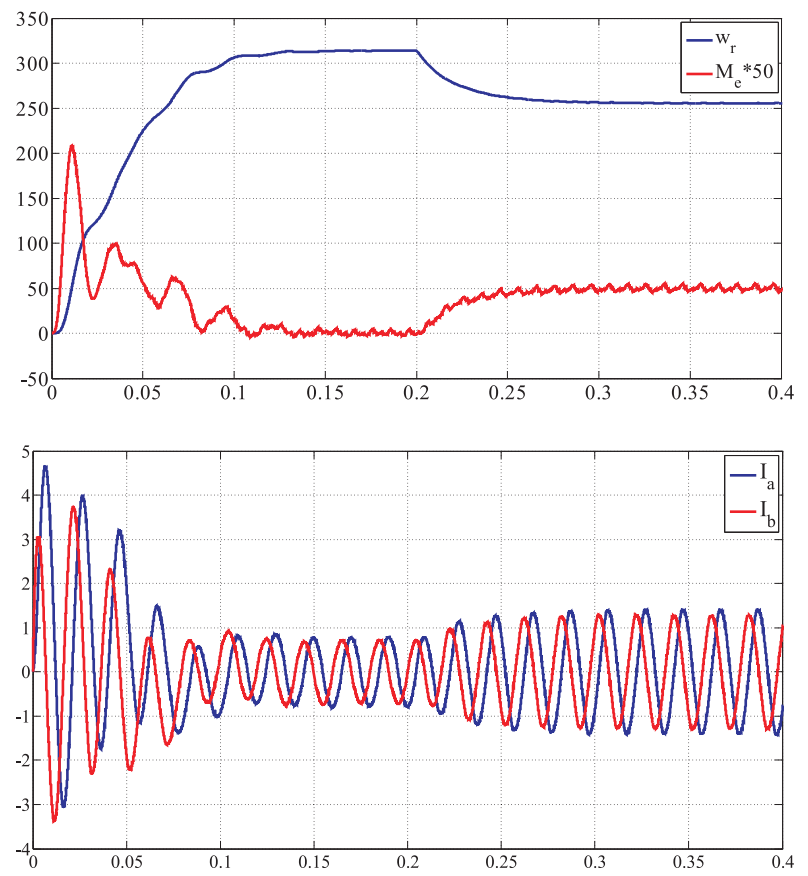

Fig. 6 Time-waveforms speed, torque and currents of TPIM during start-up

\section{Experimental verification}

The switching strategy described in previous chapter is used on the two-phase two-stage converter. The first stage was the voltage source inverter (VSI) and the second stage two matrix converters $(\mathrm{MxC})$ were realized in a bridge connection without transformer in HF interlink. In this case the matrix converter works as a cycloconverter. The block scheme and photo of converter are shown in Figs. 7 and 8.

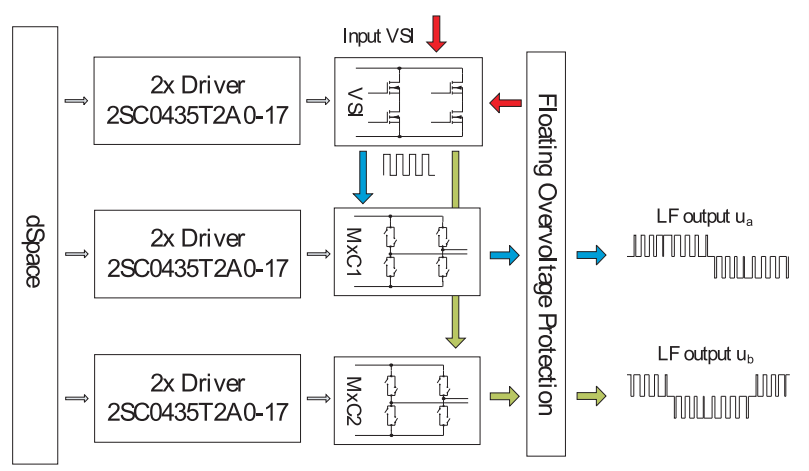

Fig. 7 Block scheme of two-stage two-phase converter with $H F \_$AC interlink and matrix converters

Figure 9 depicts output voltages and currents from the matrix converter. Yellow and blue waveforms are output voltages. Purple

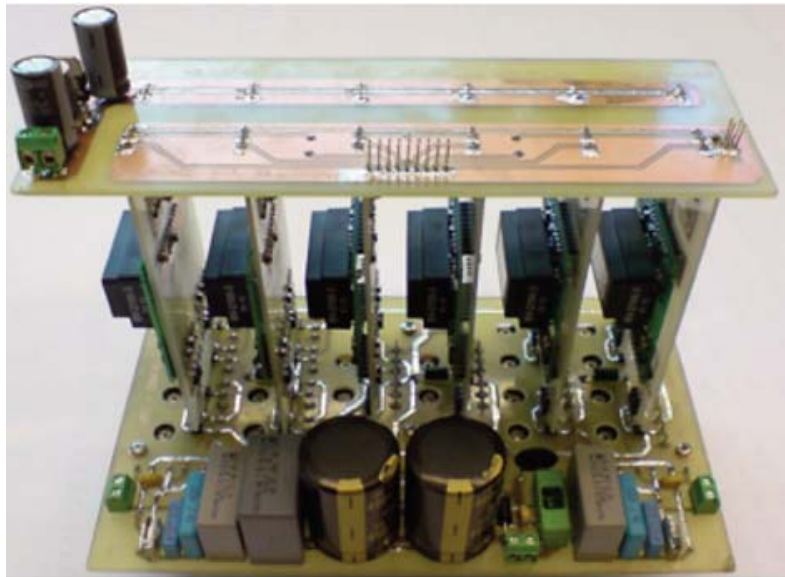

Fig. 8 Photography of complet two phase two stage converter with high-frequency AC link and ortogonal output

and green wave forms are output currents. The output phase is shifted by 90 degrees. The waveforms of current in HF interlink and output currents are shown in Fig. 10.

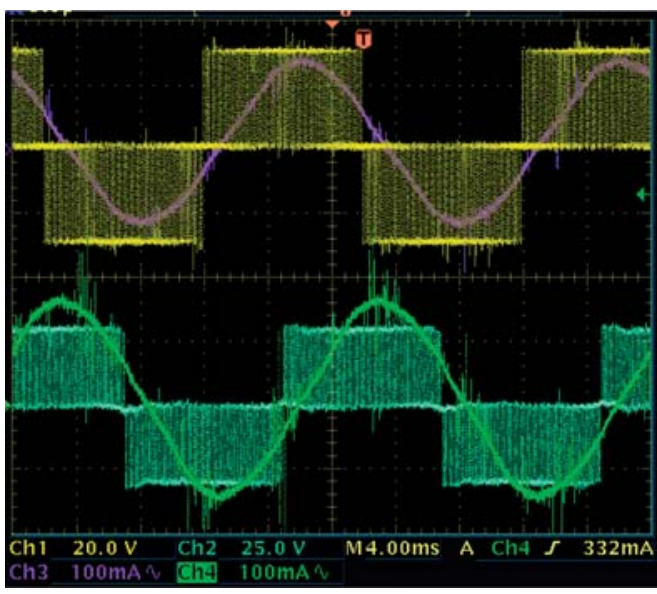

Fig. 9 Waveforms of output voltages and currents for unipolar control

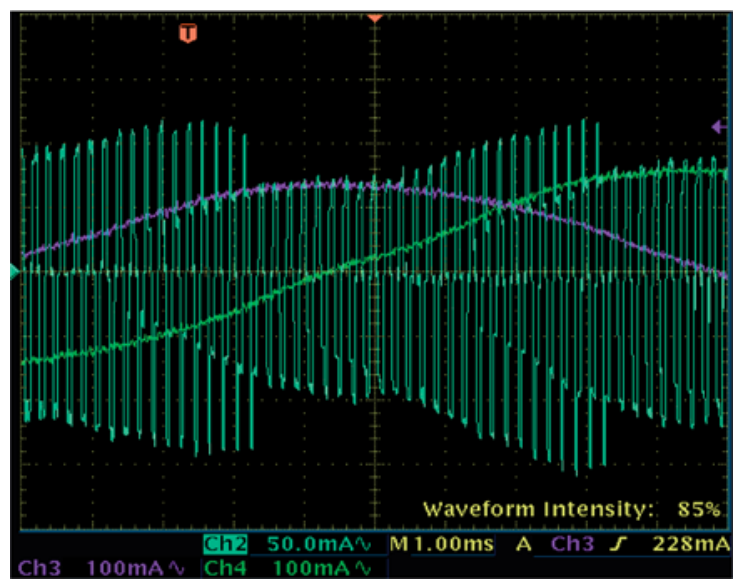

Fig. 10 Waveforms of output and HF interlink currents 


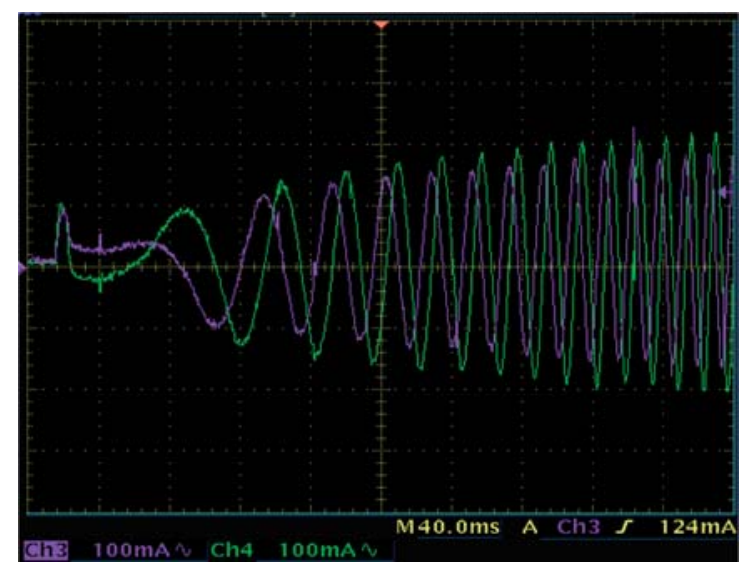

Fig. 11 Real stator currents of two-phase induction motor during start-up

From Fig. 11 we can see that the amplitudes of the stator current are not the same because the two-phase induction machine was unsymmetrical. Maximum efficiency of the proposed two-phase two-stage converter is nearly $94 \%$ at switching frequency $5 \mathrm{kHz}$ (in first-stage) and $10 \mathrm{kHz}$ (in second-stage).

\section{Conclusion}

The article shows a new concept of an electric drive system for electric vehicle and industrial application. It consists of the two-stage converter created by the single-phase converter and two single-phase matrix converters commutated by HF-AC input voltage, and two-phase induction TPIM or synchronous motors with PM. Simulation and experimental results showed good agreement between simulated and real output time waveforms. If this type of inverter is used to supply two-phase drive, high efficiency and very good mechanical parameters can be achieved (by two-phase orthogonal supply of two-phase motor - TPIM, drive develops maximum torque).The maximum efficiency of the proposed twophase two-stage converter is nearly $95 \%$ at switching frequency $1 \mathrm{kHz}$ (in first-stage) and $2 \mathrm{kHz}$ (in second-stage).

\section{Acknowledgement(s)}

The authors wish to thank for the financial support to R\&D operational program Centre of excellence of power electronics systems and materials for their components No. OPVaV- 2008/2.1/ 01-SORO, ITMS 26220120046 funded by European regional development fund (ERDF) and APVV Agency for the project No. $0138 / 10$.

\section{References}

[1] HAVRILA, R.: Analysis and Design of Single Phase Fed Matrix Converter with DSP Implementation (in Slovak), Medzinarodna studentska vedecka a odborna konferencia, Elektroenergetika a silnoprudova elektrotechnika'97, FEI STU : Bratislava, 1997, pp. 20-26

[2] DOBRUCKY, B., MARCOKOVA, M., KABASTA, M.: Using Orthogonal Transform for Solution of Matrix Converter Power Circumstances in Mathematica ${ }^{\circledR}$ Environment, Intern. Conference APLIMAT 2008, Bratislava, pp. 735-739, ISSN 1337-6365

[3] DOBRUCKY, B., BENOVA, M., FRIVALDSKY, M., PRAZENICA, M.: Choosing Modulation Strategies for 2-stage Combine LLC- and Direct Converter - Modelling, Simulation, Application, Communications - Scientific Letters of the University of Zilina, vol. 13, No. 2A, 2011, pp. 25-31, ISSN 1335-4205

[4] BENOVA, M., DOBRUCKY, B., SZYCHTA E., PRAZENICA, M.: Modelling and Simulation of HF Half-Bridge Matrix Converter System in Frequency Domain, Logistyka, 2009, No. 6, p. 87. ISSN 1231-5478

[5] DOBRUCKY, B., BENOVA, M., SPANIK, P.: Using Complex Conjugated Magnitudes - and Orthogonal Park/Clarke Transformation Methods of DC/AC/AC Frequency Converter, Electronics and Electrical Engineering, No. 5 (93), pp. 29-34, Kaunas, 2009, ISSN 1392-1215.

[6] DOBRUCKY, B., BENOVA, M., MARCOKOVA, M., SUL, R.: Analysis of Bipolar PWM Functions Using Discrete Complex Fourier Transform in Matlab, Proc. of the 17th Technical Computing Prague Conf., Prague, Nov. 2009, p. 22, ISBN 978-80-7080733-0

[7] DOBRUCKY, B., MARCOKOVA, M., POKORNY, M., SUL, R: Using Orthogonal- and Discrete Transform for Single-Phase PES Transients - a New Approach, Proc. of the $27^{\text {th }}$ IASTED Intern. Conference Innsbruck, February 2008, pp. 60-65, ISBN 978-088986-711

[8] ZASKALICKY, P., DOBRUCKY, B.: Complex Fourier-series mathematical model of a three-phase inverter with Improved PWM output voltage control; Elektronika ir Elektrotechnika, No. 7(123), 2012, pp.65-68, ISSN 1392-1215.

[9] ZASKALICKA, M., ZASKALICKY, P., BENOVA, M., ABDALMULA, M. A. R., DOBRUCKY, B.: Analysis of Complex Time Function of Converter Output Quantities Using Complex Fourier Transform/Series. Communications - Scientific Letters of the University of Zilina, No. 1(12), pp. 23-30, 2010, ISSN 1335-4205.

[10] DRGONA, P., PRIKOPOVA, A., FRIVALDSKY, M., PRIECINSKY, M.: Simulation Based Method for Design and Application of Digital Control System, Communications - Scientific Letters of the University of Zilina, vol. 13, No. 2A, 2011, ISSN 1335-4205.

[11] GANG LI, KAIN SUN, LIPEI HUANG,: A Novel Algorithm of Space Vector Modulated Two-Stage Matrix Converter, International Cobference on Electrical Machines and Systems - ICEMS 2008, pp 1316-1320, ISBN 978-1-4244-3826-6. 